ANGÉLICA FLECHAS

DERECHO YDISEÑO,

UNIVERSIDAD DE LOS ANDES

BOGOTÁ, COLOMBIA.

ANGELICA@HAPTICA.CO

JORGE GARCÍA

DERECHO,

UNIVERSIDAD DE LOS ANDES

BOGOTÁ, COLOMBIA.

JORGE.GARCIA@HAPTICA.CO

SOFÍA ESCOBAR

DERECHO,

PONTIFICIA UNIVERSIDAD JAVIERANA

BOGOTÁ, COLOMBIA.

SOFIA.ESCOBAR@HAPTICA.CO

Fecha de recepción: 23/08/2021

Fecha de aceptación: 26/11/2021

Cómo citar: Flechas, A., García, J. \& Escobar, S. (2021).

Aplicación de la metodología de Legal Service

Design de cara a contextos de derecho

público vs. derecho privado.

RChD: creación y pensamiento, 6(11), 1-23

https//doi.org/10.5354/0719-837X.2021.65499

Revista Chilena de Diseño,

RChD: creación y pensamiento

Universidad de Chile

2021, 6(11).

http://rchd.uchile.cl

\section{Aplicación de la metodología de Legal Service Design de cara a contextos de derecho público vs. derecho privado}

\author{
Application of the Legal Service Design methodology \\ in the context of public law vs. private law
}

Resumen. En Háptica hemos tenido la oportunidad de aplicar la metodología de Legal Service Design en espectros muy diversos del sector privado, los cuales involucran entre otros sectores el financiero, farmacéutico, tecnológico y retail. En el desarrollo de varios de estos proyectos, impactamos el sector público desde un rol que buscaba rediseñar la prestación de un servicio legal en un ámbito prevalecientemente privado, pero que tiene directa relación con lo público, como Diseñar documentos legales que requieren de la revisión de una entidad pública o de su uso constante, al ser una entidad de vigilancia de esta organización privada. Por otra parte, también hemos trabajado como consultores de entidades públicas, donde el objetivo ha sido rediseñar servicios y puntos de contacto legales para un contexto público de principio a fin.

De estas experiencias, y al haber tenido la oportunidad de trabajar desde la visión de Legal Service Design en el Diseño de servicios públicos y privados, buscamos comparar ambos contextos con el fin de entender las similitudes y diferencias en la aplicación de la metodología y las herramientas de Diseño legal. Por lo tanto, la idea es que, a partir de la revisión de experiencias concretas, podamos verificar si intervenir un contexto público o privado debería requerir de cambios o adaptaciones considerables en el método.

En el caso en que la respuesta a esta pregunta sea afirmativa, evaluaremos qué cambios estructurales hemos visto necesarios en el método y sus herramientas. En el caso en que sea negativa la respuesta, analizaremos en qué forma los retos de lo público se han adaptado a dichas herramientas y se ha cumplido con los objetivos no solo de Diseño sino también legales de un ecosistema público.

Palabras clave: consultoría, derecho privado, derecho público, Design thinking, fases, Legal Service Design, medición, metodología, oportunidades de innovación, puntos de contacto, rediseño de servicios, servicios legales, usuario

\footnotetext{
Abstract. At Háptica we have had the opportunity to apply the Legal Service Design methodology in very diverse contexts in the private sector, including the financial, pharmaceutical, technology and retail sectors, among others. In the development of these projects, we impacted the public sector from a role that sought to redesign the provision of a legal service in a predominantly private sphere, but directly related to the public sphere, such as designing legal documents that require the review of a public entity or constant use as a surveillance entity of a private organization. Along the same path, we have also been in the direct role of consultants for public
} 
entities, in which services and legal touch points were developed for a public context from beginning to end.

From these experiences, and having the opportunity to work from the Legal Service Design vision in the Design of public and private services, considering their various nuances, we have identified the need to analyze the differences between both contexts when using this approach's methodology and tools. Therefore, from our experience in the use of these resources, we want to reflect on the application of these legal Design inputs by reviewing specific experiences, and verifying if an intervention in a public or private context should require changes or considerable adaptations in the method.

In the event that the answer to this question is affirmative, we will evaluate what structural changes in the method and its tools we have identified as necessary. In the event that the answer is negative, we will analyze how public challenges have been adapted to these tools, to make sure not only the Design objectives, but also the legal objectives of a public legal ecosystem have been met.

Keywords: consulting, Design thinking, innovation opportunities, legal services, Legal Service Design, measurement, methodology, phases, private law, public law, service redesign, touch points, user 


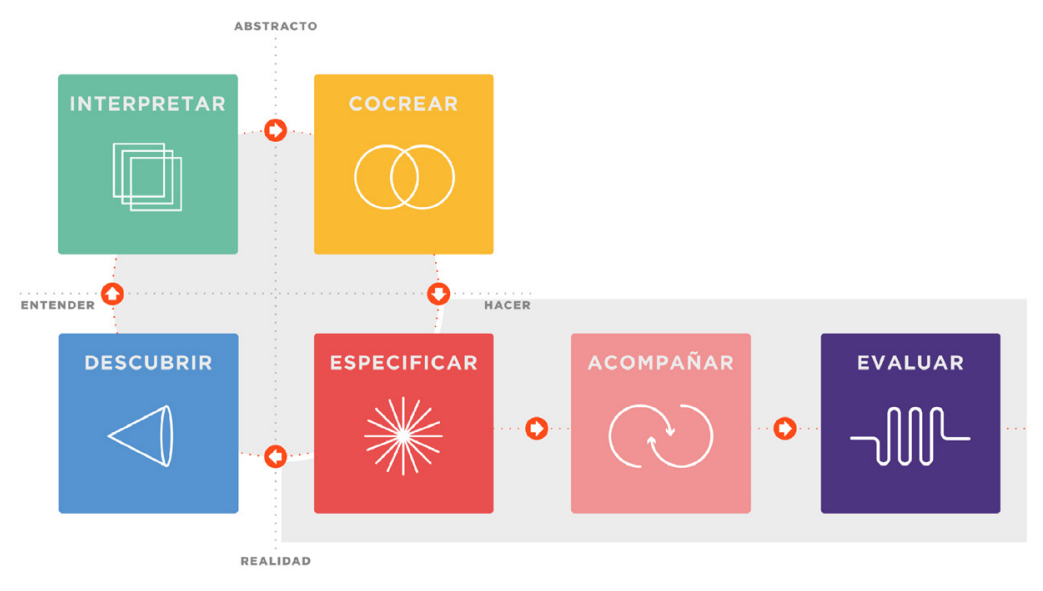

\section{Introducción: Tesis}

\section{¿A qué nos referimos con Legal Service Design?}

Legal Design es una visión metodológica aplicable a proyectos de consultoría, cuyo objetivo es el rediseño de servicios legales. Esta aproximación al Diseño de servicios ha sido desarrollada desde los campos de estudio del derecho y el Diseño. Desde el Diseño, su referenciación inició en el laboratorio de Diseño legal de la Universidad de Stanford, a cargo de Margaret Hagan, además de autores, profesionales del derecho y del Diseño que han trabajado por definir su marco conceptual. Desde el derecho también ha habido importantes avances en la forma en la que se plantea la estrategia de redacción y uso de los documentos, como veremos más adelante.

En Háptica ${ }^{1}$ hemos incluido la palabra service a la metodología de Legal Design, para llegar a Legal Service Design, pues entendemos que la economía actual se basa en servicios y que todo a nuestro alrededor opera a través de uno, lo cual también es conocido como la lógica dominante del servicio (Penin, 2018). Por esta razón, todas nuestras aproximaciones a un proyecto parten del entendimiento del servicio, sus momentos y sus puntos de contacto legales para lograr intervenciones que sean implementables y generen un impacto real.

En consecuencia, para trabajar la metodología de Legal Service Design, partimos del método de Design Thinking planteado en el artículo "Innovation as a learning process" (Beckman \& Barry, 2007), en el que hay cuatro fases principales: Descubrir, Interpretar, Crear frameworks y Prototipar. Lo anterior, con el fin de partir de un entendimiento de los requerimientos del usuario para encontrar oportunidades de innovación, que después serán trabajadas en sesiones de cocreación y posteriormente esas ideas serán materializadas en prototipos que se someterán a validación con usuarios.

Para profundizar sobre la forma en la que hemos trabajado en contextos públicos y privados presentamos cuatro casos: dos del sector público (Unidad de Gestión de Pensión y Parafiscales [UGPP] y Osiptel) y dos del sector privado (Bancolombia y Gómez Pinzón). A su vez, estos casos están clasificados según su finalidad: dos buscaban trabajar el rediseño de documentos (Bancolombia y Osiptel) y los otros dos buscaban formar a los integrantes de la organización en la metodología (UGPP y Gómez Pinzón). Si tenemos en cuenta esta combinación, lograremos entender si es necesario hacer una diferenciación
Figura 1. Esquema de la metodología de Design Thinking trabajada por Háptica (elaboración propia inspirada en el trabajo de Beckman y Barry, "Innovation as a Learning Process", 2007)

1. Consultora de Diseño de servicios con más de siete años de experiencia, ubicada en Bogotá, Colombia. 
Figura 2. Sesiones de discusión sobre el expediente, el objetivo era encontrar las oportunidades de innovación en los documentos de la entidad (Háptica, 2017)

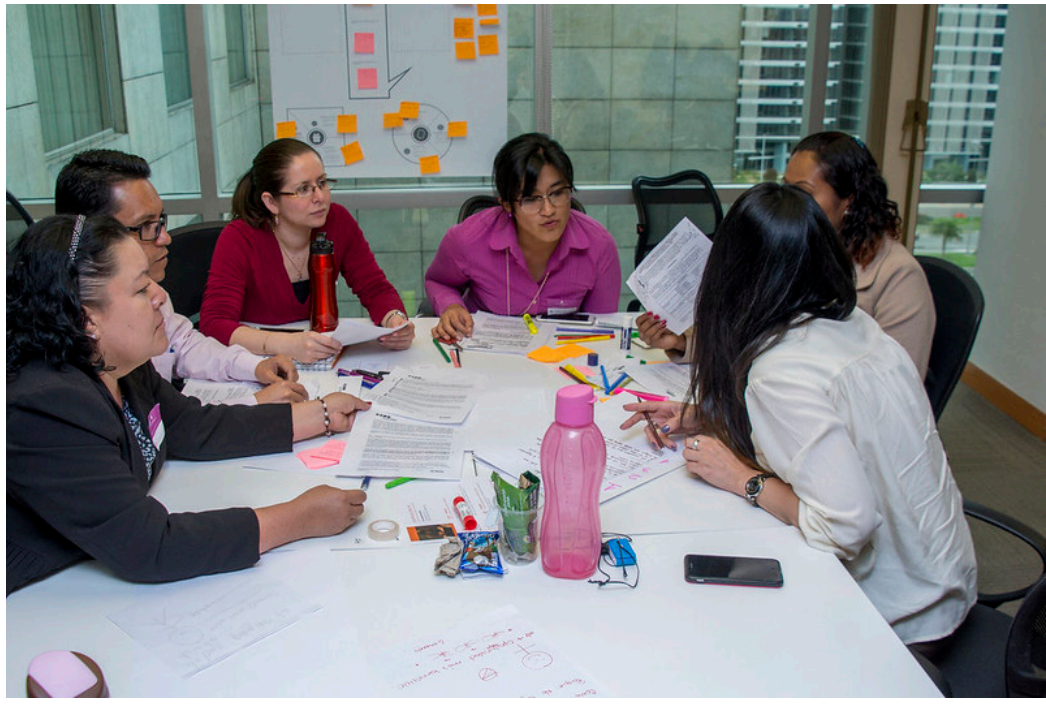

\section{UGPP: sector público, formación}

Cliente UGPP (Unidad de Gestión de Pensión y Parafiscales)

Objetivo Formar a los funcionarios en la metodología de Legal Service Design, con el fin de que entendieran la realidad de sus usuarios cuando estos realizan cualquier trámite ante la entidad.

Metodología

Talleres metodológicos por medio de los cuáles los integrantes de las entidades pudieran conocer los dolores de los ciudadanos al interactuar con los actos administrativos, tuvieran la libertad de rediseñarlos y de ponerlos a prueba..

Herramientas

Expedientes que resumen las historias de los usuarios, Value Proposition, ¿Cómo lo haría o lo contaría?, Paper prototyping, cartilla de lenguaje claro.

en la aplicación de la metodología de Legal Service Design cuando se utiliza en el contexto del sector público versus cuando es aplicada en casos del sector privado.

A continuación, se presentan los cuatro proyectos con sus metodologías.

\section{Metodología y resultados}

\section{UGPP: sector público, formación}

En el 2017, la UGPP nos dio la oportunidad de desarrollar uno de los primeros proyectos de formación con la mirada de Legal Service Design. El objetivo era formar a los funcionarios en la metodología, con el fin de que entendieran la realidad de sus usuarios cuando estos realizan cualquier trámite ante la entidad, y así generar un cambio organizacional. Era necesario que los funcionarios propusieran nuevas ideas y soluciones para promover la lectura y la comprensión real de los actos administrativos (documentos que representan actuaciones o la voluntad de la administración pública), ya que para ese momento se había identificado estadísticamente que no eran comprendidos en su totalidad por los ciudadanos. La entidad quería atacar esta problemática, ya que a través de estos documentos se tomaban decisiones frente a derechos o sanciones que afectaban de manera directa 


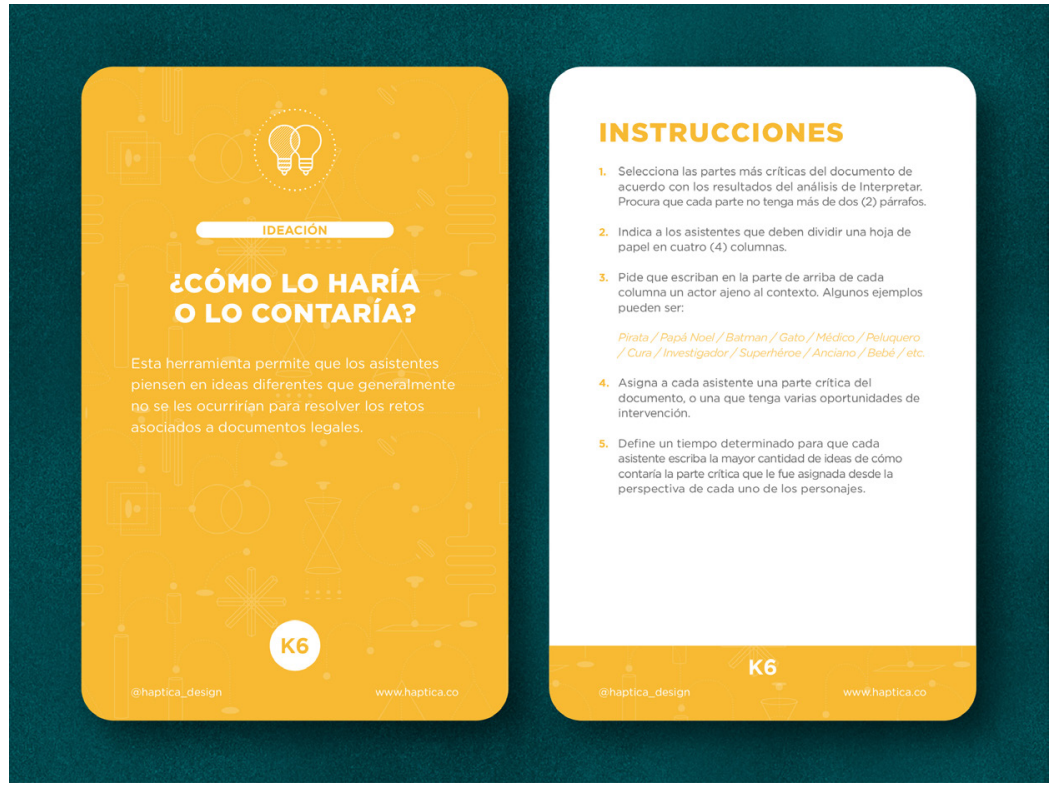

los intereses de la personas y compañías. La información no generaba mayor respuesta por parte de ellos, por su falta de entendimiento o por su complejidad para resolver la situación o cumplir con el comunicado. Este dolor que se presenta constantemente en contextos de prestación de servicios legales.

La metodología consistía en los siguientes módulos: inspirar, analizar, interpretar, cocrear y proponer.

En la etapa de inspirar se introdujo el concepto de Legal Service Design a todos los participantes. Fue importante presentar la metodología, desde la teoría de la academia y también desde casos aplicados en Háptica. Para esto se presentó la relevancia del Diseño como aproximación metodológica, su lógica centrada en las personas y en su acercamiento a los proyectos desde una perspectiva convergente y divergente. Posteriormente, se explicó el concepto de servicio y de los puntos de contacto legales, para llegar finalmente a la posibilidad de Diseñar estos, pues también son usados por personas que no son necesariamente abogados.

Esta visión del derecho nos exige crear nuevos puntos de contacto y redactar documentos legales que inviten a los usuarios sin conocimiento legal a interactuar y usar estos elementos como herramientas útiles en sus actividades del día a día. Analizamos casos de éxito y elementos de Diseño sobre forma y comunicación, siguiendo un paso a paso que se llevó a cabo en el taller.

En el segundo módulo, analizar, los participantes del taller fueron organizados en distintos grupos y cada uno tuvo asignado un caso (expediente) que trabajaron a lo largo del espacio. Luego, en interpretar, con la información descubierta en el expediente, los asistentes encontraron patrones de comportamiento en los ciudadanos frente a los actos administrativos. En cocrear, los asistentes buscaron nuevas ideas de Diseño que estuvieran basadas en las necesidades reales y comportamentales de los ciudadanos.
Figura 3. Herramienta: ¿Cómo lo haría o lo contaría? (Háptica, 2021) 
Figura 4. Funcionaria en proceso de reescribir uno de los contenidos legales (Háptica, 2017)

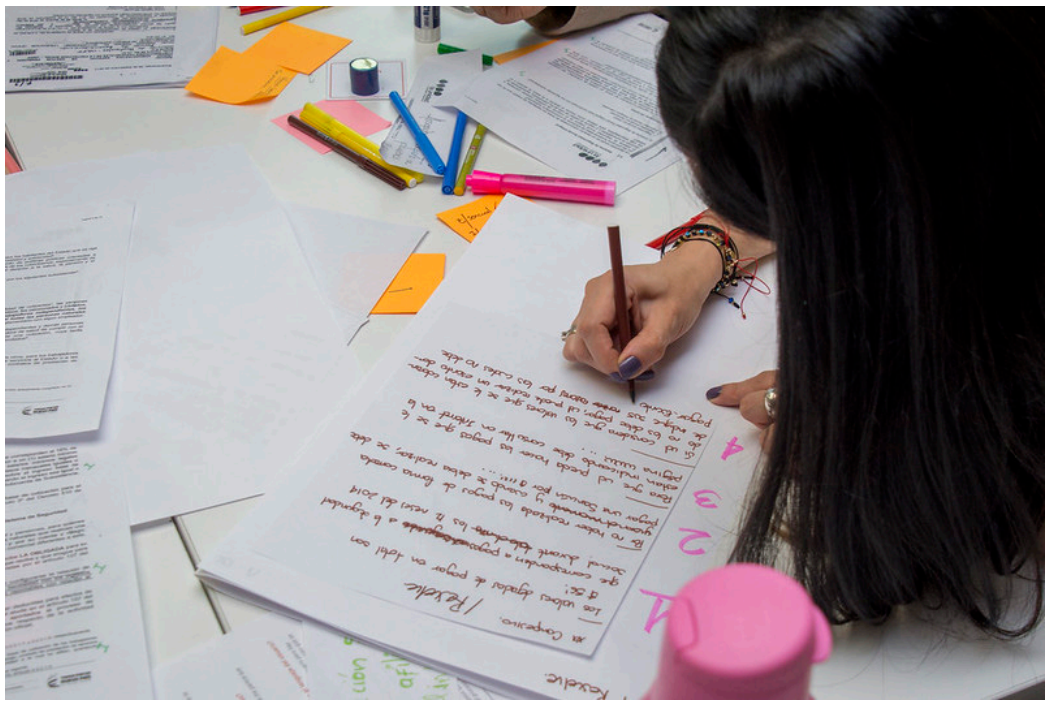

Una de las herramientas que usamos en estos ejercicios creativos se llama ¿Cómo lo haría o lo contaría?, donde pensamos en actores extremos para obtener inspiración. En el caso de la UGPP pensamos en usuarios como personas mayores o con un nivel de alfabetización baja, para que se pusieran en sus zapatos y simplificaran al máximo sus soluciones.

Todas estas actividades nos permitían divergir en ideas y explorar al máximo las posibilidades de solución, para luego pasar a converger en soluciones viables y factibles para el cliente.

Finalmente, en el módulo de proponer, los asistentes volvieron tangibles los resultados de los ejercicios realizados en las fases anteriores, en una propuesta de Diseño que diera a conocer el entendimiento del acto administrativo. De este módulo también resultaron unas reglas de oro de comunicación asertiva que serían aplicadas posteriormente en cualquier tipo de comunicación que los funcionarios de esta entidad emitieran. Bajo esta metodología, se desarrollaron diez talleres con un total de 485 personas capacitadas, en los que se generaron 60 propuestas de Diseño que se concretaron en 12 actos administrativos.

Cuatro años después de haber trabajado con la UGPP nos encontramos con unos resultados fascinantes dentro de la entidad. Luz Dary Mendoza, Directora de Servicios Integrados de Atención, junto con los Directores de las áreas misionales de la entidad de pensiones y parafiscales, nos cuentan que durante estos cuatro años han rediseñado una gran variedad de oficios y actos administrativos en temas pensionales y parafiscales, mediante la implementación de la metodología. También nos contaron que intervinieron los canales a través de los cuales se comunican con sus usuarios, como su página web (La Unidad de Pensiones y Parafiscales [UGPP], 2021). Adicionalmente, modificaron el mecanismo para la medición de la calidad percibida por los usuarios de los canales de atención a través de distintos indicadores estratégicos; el más relevante es el indicador de claridad de la información suministrada, que representa el grado de entendimiento que tiene el ciudadano con respecto a la información brindada a través de los 


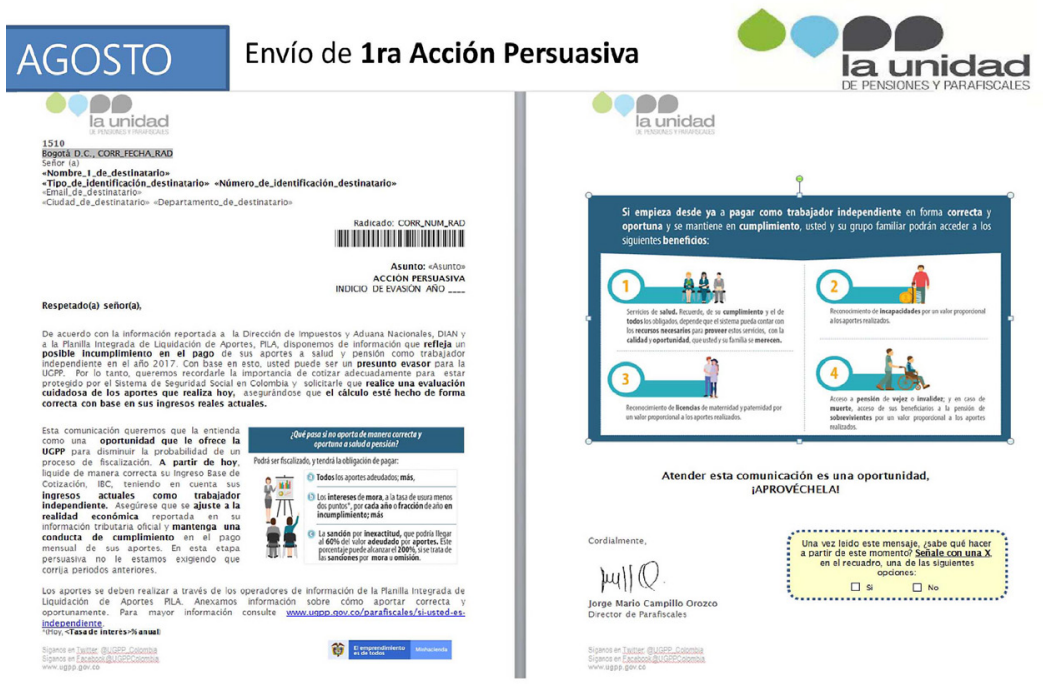

canales de atención, los oficios y/o actos administrativos expedidos por cada una de las áreas misionales de la entidad.

Esto demuestra que el impacto generado por este proyecto no solo se ha quedado en el rediseño y simplificación del lenguaje de sus documentos jurídicos. En este caso específico, la forma en que la UGPP se relaciona con sus usuarios ha trascendido de los actos administrativos al uso de múltiples herramientas para impactar la experiencia de los ciudadanos de manera positiva.

En sus palabras, Luz Dary nos cuenta que:

La UGPP en Colombia ha trabajado por mejorar la experiencia de nuestros ciudadanos, específicamente en el relacionamiento con la entidad.

Principalmente, hemos trabajado por generar una mayor cercanía, por esta razón, la entidad incursionó en la metodología de Legal Service Design, con el fin de entender la experiencia que viven los usuarios de la entidad y aprender acerca de la importancia del lenguaje claro frente a las comunicaciones con nuestros usuarios y como los atendemos en nuestros canales de atención con un lenguaje sencillo y claro, teniendo presente que en los trámites de la entidad hay un componente jurídico complejo y que se brinda información al ciudadanos de manera verbal o escrita sobre las peticiones de los ciudadanos.

Es por ello, que en la UGPP seguimos trabajando por mejorar la experiencia de nuestros ciudadanos a través de nuestros servicios. La parte fundamental siempre será brindarles información clara, sencilla y fácil de entender y el gran reto es que no tengan que acudir a terceros para la explicación de un trámite con la entidad y es por esto, que en estos años hemos incursionado en este cambio y sin duda seguiremos trabajando para seguir impactando de manera positiva la experiencia de nuestros ciudadanos. (Entrevista personal, fecha) 


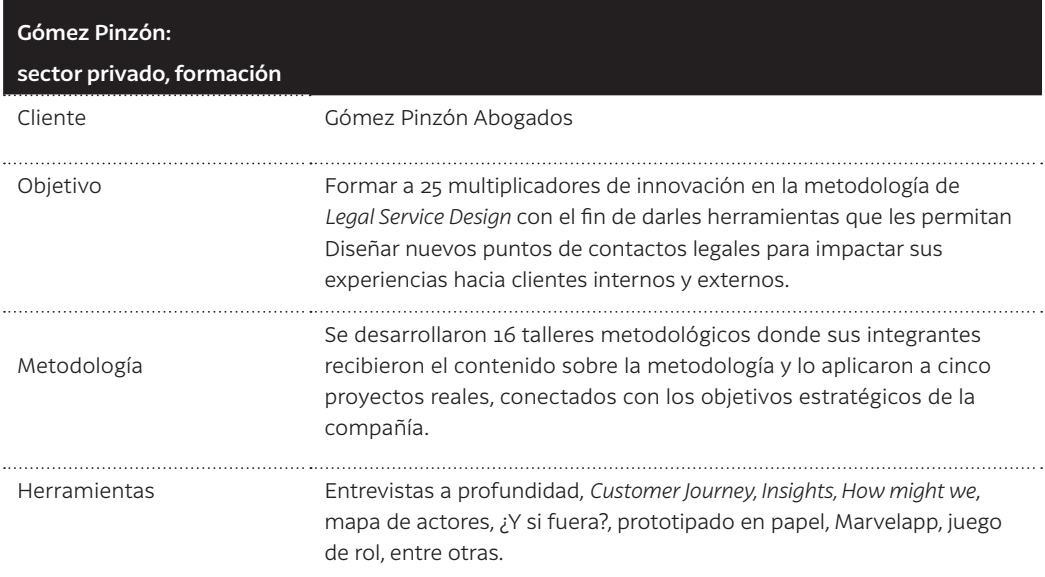

El primer reto fue seleccionar a los 25 multiplicadores de innovación que tenían la misión de recibir la formación. Una vez conformado el equipo, durante cuatro meses, nos reunimos 16 veces en sesiones de cuatro horas que les permitieron a los abogados e integrantes de otras áreas misionales aprender las diferentes fases de la metodología y sus herramientas. Así, identificaron la importancia de hacer trabajo de campo con sus clientes y de ver las necesidades de sus compañeros para dejar de lado una visión de firma e introducir una perspectiva más humana. Participaron en talleres para identificar insights en el servicio y no solamente generaron ideas en talleres de cocreación, sino que lideraron estos espacios con actores internos y externos a la compañía. Como resultado, no solo llegaron a soluciones que resolvían los retos de la organización; también tuvieron la oportunidad de materializar estas ideas en prototipos que sometieron a validación con estos actores.

Una de las herramientas que más usaron dentro del ejercicio de prototipado es Marvelapp (Marvelapp, 2021), que sirvió para validar la interacción de las soluciones que estaban pensadas para el canal digital. Para lograrlo, primero dibujaron las pantallas que correspondían a la solución que resolvía el problema identificado, después las subieron a la plataforma para determinar cuál sería la principal y cuáles serían las internas. Finalmente, Marvelapp genera un enlace que se le puede enviar a clientes externos e internos con el fin de validar si la experiencia de interacción es la adecuada y si es necesario continuar la iteración de la solución.

Entre los resultados generados por este proyecto están los cinco prototipos generados por los integrantes de la organización, que fueron validados con los actores relevantes como clientes o usuarios internos. Dentro de las iniciativas había nuevos programas de entrenamiento, herramientas digitales para facilitarle la vida a los clientes y, sobre todo, a los abogados y actores del área misional que se ahogan en las labores administrativas de la firma. Así mismo, se crearon nuevos procesos para desarrollar el proceso de retroalimentación dentro de la compañía.

Esto no fue lo único que ocurrió. Como parte del proyecto, también se desarrolló una presentación final estilo Shark Tank (tanque de tiburones) con el fin de que la propuesta que tuviera mayor afinidad con las necesidades 

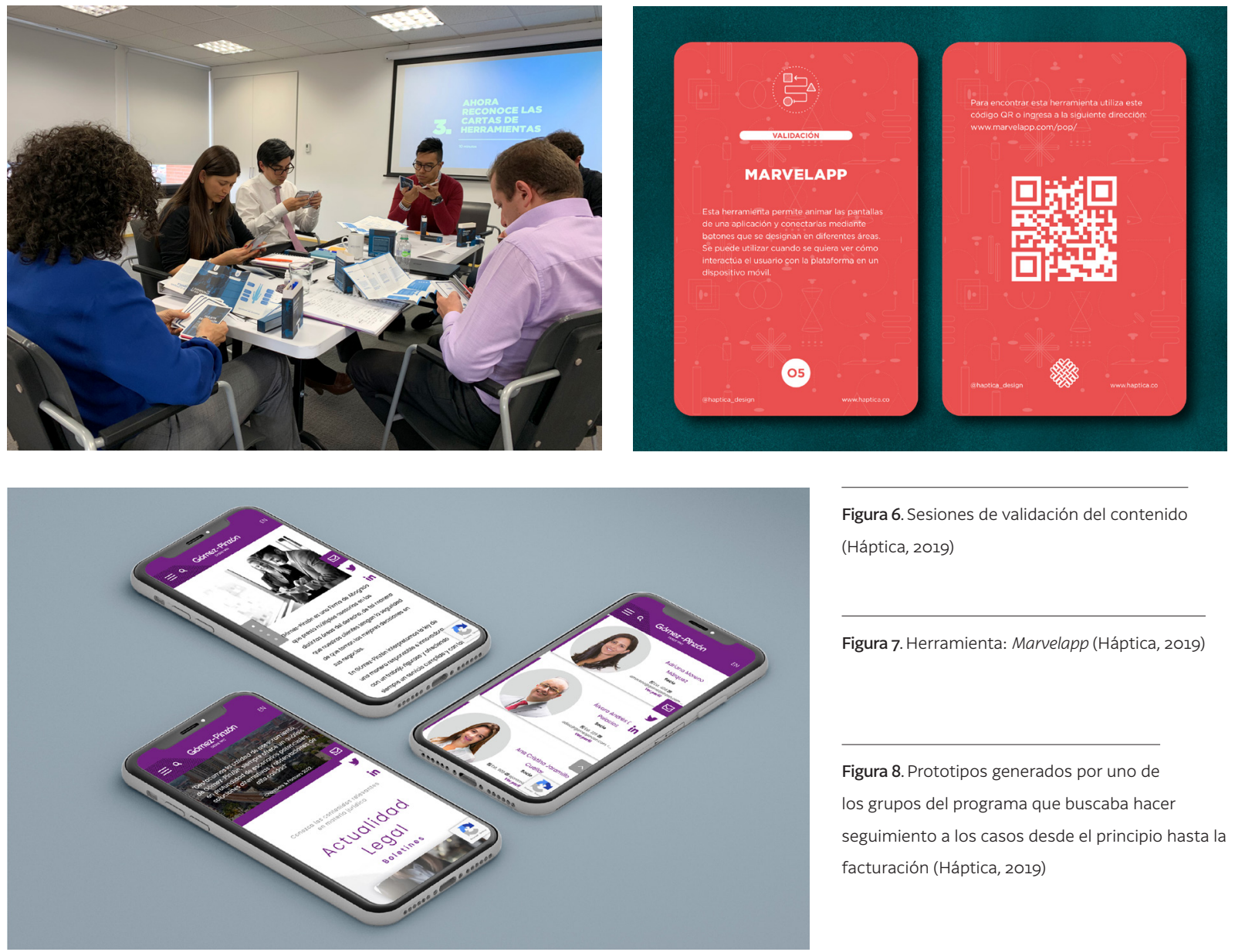

Figura 6. Sesiones de validación del contenido (Háptica, 2019)

Figura 7. Herramienta: Marvelapp (Háptica, 2019)

Figura 8. Prototipos generados por uno de los grupos del programa que buscaba hacer seguimiento a los casos desde el principio hasta la

de la organización recibiera inversión por parte de la compañía. En este espacio fueron invitados tres socios que jugaron el rol de jurados o Sharks y los empleados de la firma como público, con el fin de que los multiplicadores pudieran presentar sus proyectos y pusieran en práctica los conocimientos aprendidos asociados a storytelling (cuentacuentos) y venta de proyectos. Al finalizar la jornada, fue necesario aumentar el presupuesto en un $50 \%$ con el fin de garantizar que dos de las propuestas recibieran inversión. Esto representó un hito para la cultura de la innovación de la firma, pues le permitió a toda la organización enterarse del proceso, los involucrados, los resultados y su interés asociado al mismo.

Actualmente dos de los proyectos incubados son desarrollados internamente y Gómez Pinzón es una firma que ofrece servicios de Legal Design en algunos de sus entregables con clientes. En el Diseño de documentos se ha visto el mayor campo de aplicabilidad, pues es mucho más conciso y fácil de digerir para el cliente, y facilita la interacción con los interlocutores de la información, lo cual genera un aumento en la demanda de este tipo de servicios.

"Los reguladores tienden a esperar un mandato legal, una sugerencia de otro funcionario o agencia gubernamental, o una petición de una persona externa antes de iniciar el proceso para cambiar una regla existente o redactar una 
Figura 9. Memorias del trabajo de campo (Háptica, 2018)

\begin{tabular}{|c|c|}
\hline $\begin{array}{l}\text { Osiptel: sector } \\
\text { consultoria }\end{array}$ & \\
\hline Cliente & Osiptel \\
\hline Objetivo & $\begin{array}{l}\text { Rediseñar los lineamientos de los contratos de telefonía móvil dentro } \\
\text { del Perú porque los usuarios aceptaban sus términos, pero no los leían, } \\
\text { o si los leían, no los entendían. }\end{array}$ \\
\hline Metodología & $\begin{array}{l}\text { Visitamos Perú durante una semana, realizamos trabajo de campo, se } \\
\text { construyeron expedientes para presentar los resultados, se lideraron } \\
\text { sesiones de cocreación con los integrantes de la organización y se } \\
\text { aterrizaron prototipos que fueron validados con usuarios reales, para } \\
\text { crear los nuevos lineamientos de los contratos de telefonía móvil para } \\
\text { Perú. }\end{array}$ \\
\hline Herramientas & $\begin{array}{l}\text { Entrevistas a profundidad, entrelíneas, expedientes que resume las } \\
\text { historias de los usuarios, insights, value proposition, simple matemática, } \\
\text { prototipado en papel. }\end{array}$ \\
\hline
\end{tabular}

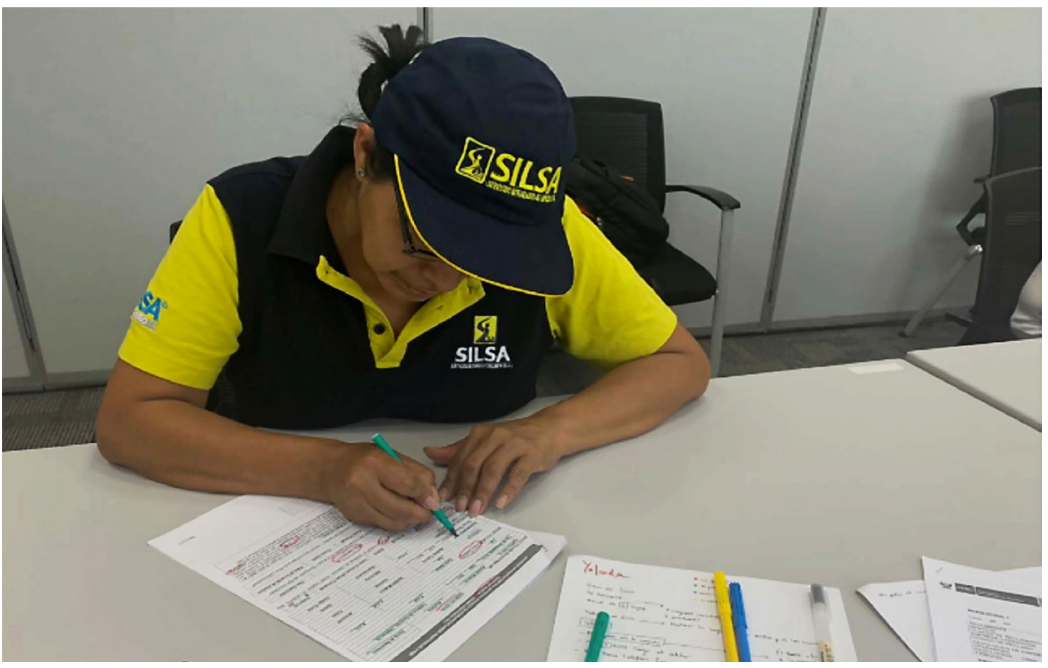

nueva" (Armitage, Cordova \& Siegel, 2017). Este no era el caso de Osiptel. A partir de esta situación el área de innovación de la entidad decidió buscar una solución a través de un proyecto de consultoría que buscaba Diseñar una nueva guía para los términos y condiciones que los operadores de telefonía móvil debían incluir en sus procesos comerciales.

Este proyecto inició con un viaje a Perú para realizar el trabajo de campo durante dos días. Usamos distintas herramientas con el fin de diagnosticar los documentos actuales e identificar qué no entendían los usuarios de los documentos, por qué los aceptaban, qué quisieran que fuera diferente, etc.

Dentro de las herramientas seleccionadas para desarrollar el trabajo de campo se encuentra Entrelíneas, que consiste en entregarle tres colores al entrevistado para que subraye con rojo todo lo que no entiende del documento, con amarillo lo que le sobra y con verde lo que le genera valor, con el fin de poder comparar estos contenidos entre todos los entrevistados y poder tomar decisiones asociadas a los contenidos presentes en los documentos sujetos a análisis. En este caso, fue una gran técnica que permitió a usuarios de diferentes perfiles comunicar con qué componentes se sentían cómodos y con cuáles no. 

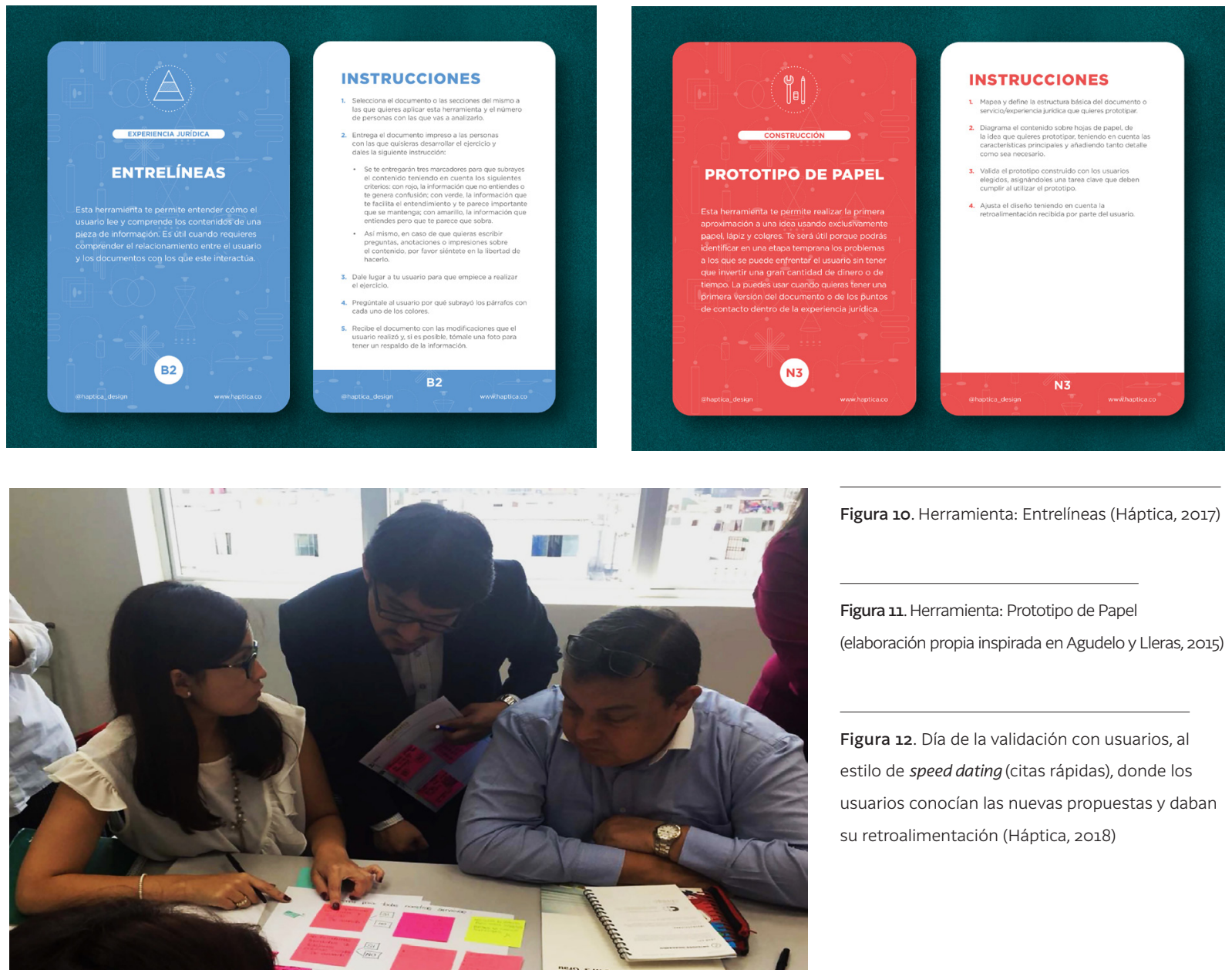

Figura 10. Herramienta: Entrelíneas (Háptica, 2017)

Figura 11. Herramienta: Prototipo de Papel

(elaboración propia inspirada en Agudelo y Lleras, 2015)

Figura 12. Día de la validación con usuarios, al estilo de speed dating (citas rápidas), donde los usuarios conocían las nuevas propuestas y daban su retroalimentación (Háptica, 2018)

Una vez terminado el trabajo de campo, los asistentes a los talleres de formación recibieron unos expedientes con los cuales debían trabajar en las siguientes fases de la metodología y luego aplicarla al caso de estudio que era el foco de todo el proyecto. Posteriormente, presentamos la etapa de interpretar, cuyo objetivo era analizar las tareas de los usuarios, sus dolores y ganancias perseguidas cuando buscaban servicios de telefonía móvil y se enfrentaban al proceso legal que este incluye. Estos insumos los comparamos con la experiencia que ofrece el documento actualmente y validamos si incluía mitigadores de dolor o generadores de ganancia. En el resultado encontramos unos vacíos en la experiencia que nos llevaron a construir las oportunidades de innovación en el documento.

Estas oportunidades las llevamos a la sesión de creatividad. Esta etapa buscaba que se imaginaran diferentes formatos para resolver el reto creativo. Por ejemplo, podría ser un protocolo adicional, una herramienta tecnológica, un rol que debe cumplir algún actor del ecosistema, etc.

Una vez depurada la información, logramos una visualización mucho más amigable y construimos los prototipos. Usamos principalmente la herramienta de prototipado en papel, con el fin de aterrizar rápidamente las 


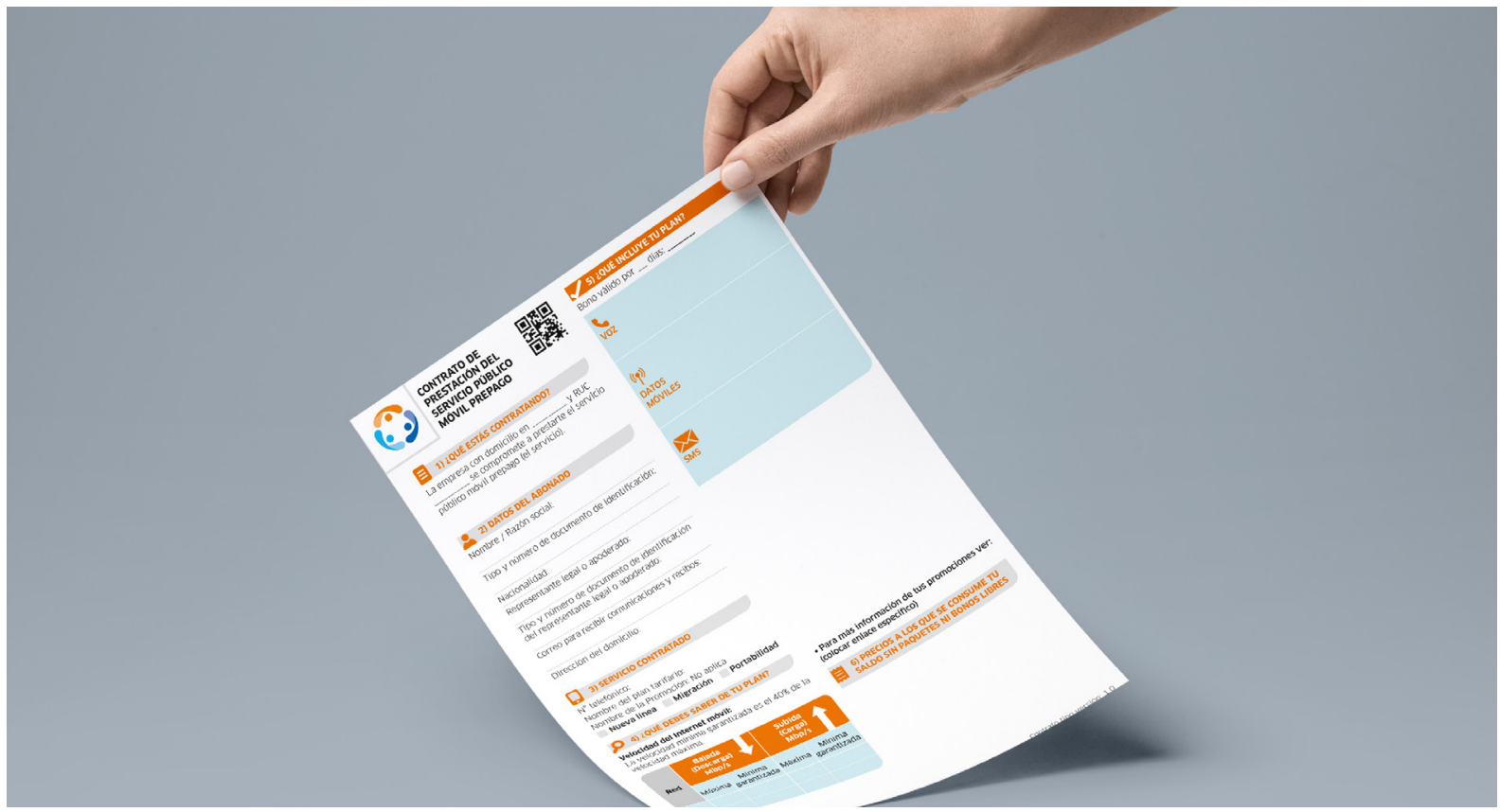

Figura 13. Ejemplo de uno de los nuevos contratos que pueden firmar los peruanos cuando quieren adquirir servicios de telefonía móvil (Ospitel, 2018) ideas y lograr la validación con los usuarios que hicieron parte del trabajo de campo inicial (Snyder, 2003). En este caso, fue fundamental usar solo papel porque teníamos sólo una semana para vivir toda la metodología y necesitábamos aprender rápido del modelo, así fuera con post-its, tijeras y pegante. De esta forma, los abogados de la entidad pública transformaron los contratos y pudieron crear nuevas versiones rápidamente, y aprender del usuario y su interacción con los nuevos documentos en tiempo real.

Como resultado, se generaron unas reglas de oro para crear términos, condiciones y contratos para los servicios de telefonía móvil con el fin de que los operadores en Perú realmente lograran que los usuarios los leyeran $y$, sobre todo, los entendieran. Algunos de los determinantes fueron: la eliminación de contenidos técnicos relacionados con el mundo legal y tecnológico, y que al menos el 40\% del contrato debía ser gráfico, entre otros.

Como respuesta a estos planteamientos, Noemi Espinoza, especialista en inversiones y procesos de innovación en Osiptel, junto a diferentes áreas de la entidad, inició la tarea de llevar estos determinantes a la realidad. Logró instaurar una nueva cultura en las empresas operadoras y generó las guías obligatorias que deben seguir los operadores de telecomunicaciones (Resolución de Consejo Directivo 153-2020-CD/OSIPTEL, 2020), donde se definieron las características del contrato tipo, el tiempo mínimo de revisión, la obligación de pasar el documento para ser revisado por Osiptel antes de la comercialización el producto y la prohibición de incluir cláusulas adicionales a las que se mencionan en el contrato tipo.

Con esto se buscaba resolver la desigualdad de información que había antes frente a la disparidad de contenidos entregados en los diferentes documentos legales que hacían parte de los operadores de telefonía móvil. 


\section{Bancolombia: sector}

privado, consultoría

\begin{tabular}{ll} 
Cliente & Osiptel \\
Objetivo & $\begin{array}{l}\text { Rediseñar tres documentos de alto impacto para el banco: uno } \\
\text { masivo, otro que se relacionaba con el mercado de valores y un } \\
\text { último que tenía que ver con negocios fiduciarios para garantizar } \\
\text { proyectos licitatorios con el Estado. }\end{array}$ \\
\hline Metodología & $\begin{array}{l}\text { Entendimiento del ecosistema actual involucrado en la construcción } \\
\text { de los documentos, que se relaciona actualmente con ellos, con el } \\
\text { fin de cocrear la nueva versión de los documentos. }\end{array}$ \\
\hline Herramientas & $\begin{array}{l}\text { Entrevistas a profundidad, cartografía del ecosistema legal, } \\
\text { entrelíneas, sombra, insights, journey jurídico, ADN del servicio, } \\
\text { perfilación. }\end{array}$
\end{tabular}

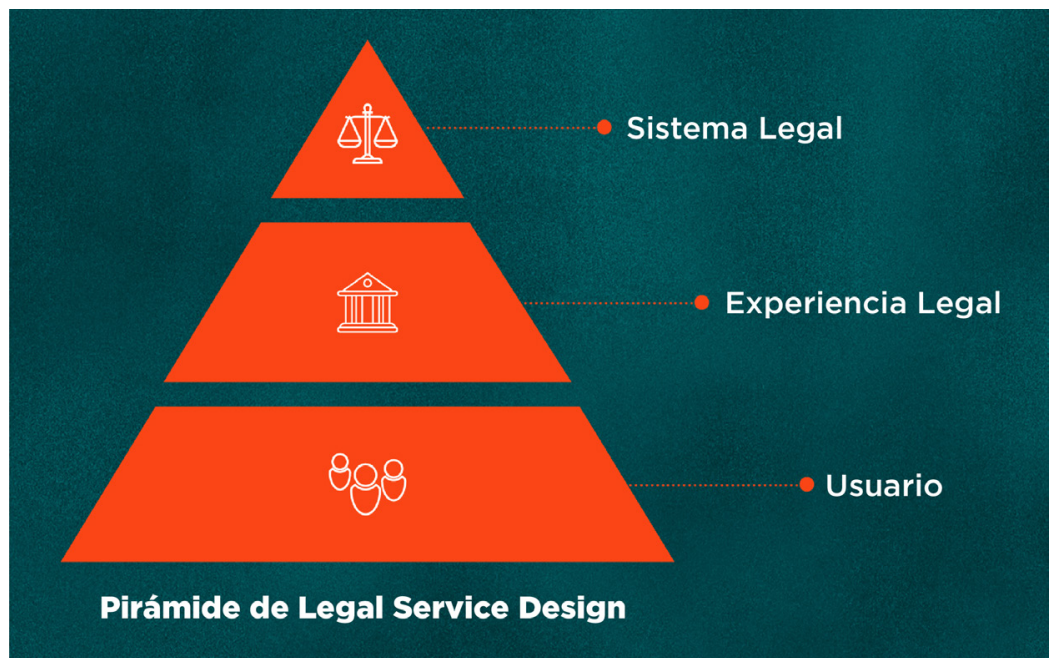

Gracias a esto se lograron "más de dos millones de nuevas contrataciones de servicios móviles y fijos en el territorio nacional empleando los contratos cortos (contratos tipo). La adopción de este contrato corto en el mercado fue equivalente al $83 \%$ del total de 2,51 millones de contrataciones de servicios efectuadas en el sexto mes del año, de acuerdo con lo reportado por las empresas Claro, Entel, Bitel y Telefónica. Es decir, ocho de cada diez contrataciones nuevas de los servicios de telecomunicaciones emplearon los contratos cortos" (Oficina de Comunicaciones y Relaciones Institucionales, 2021).

Bancolombia necesitaba ofrecer soluciones que fueran más allá de simplemente poner las palabras en un lenguaje más claro y comprensible. Por esta razón, más que Diseñar el documento, el proyecto se aproximó al reto de analizar la experiencia general de los usuarios con el producto. En ese sentido el servicio legal que diseñamos no era la relación de los usuarios con el documento, sino cómo éste podía sostener una mejor experiencia de venta y relacionamiento durante toda la vida útil del documento entre los usuarios (cliente - abogado comercial - partes en el contrato - áreas operativas del banco).

Para la fase de investigación de campo se hizo una comprensión del contexto completo de la experiencia que queríamos mejorar. Para facilitar el proceso, usamos la pirámide de Legal Service Design de Háptica para visualizar los diferentes niveles de información.
Figura 14. Herramienta: pirámide de Legal Service (Háptica, 2021) 

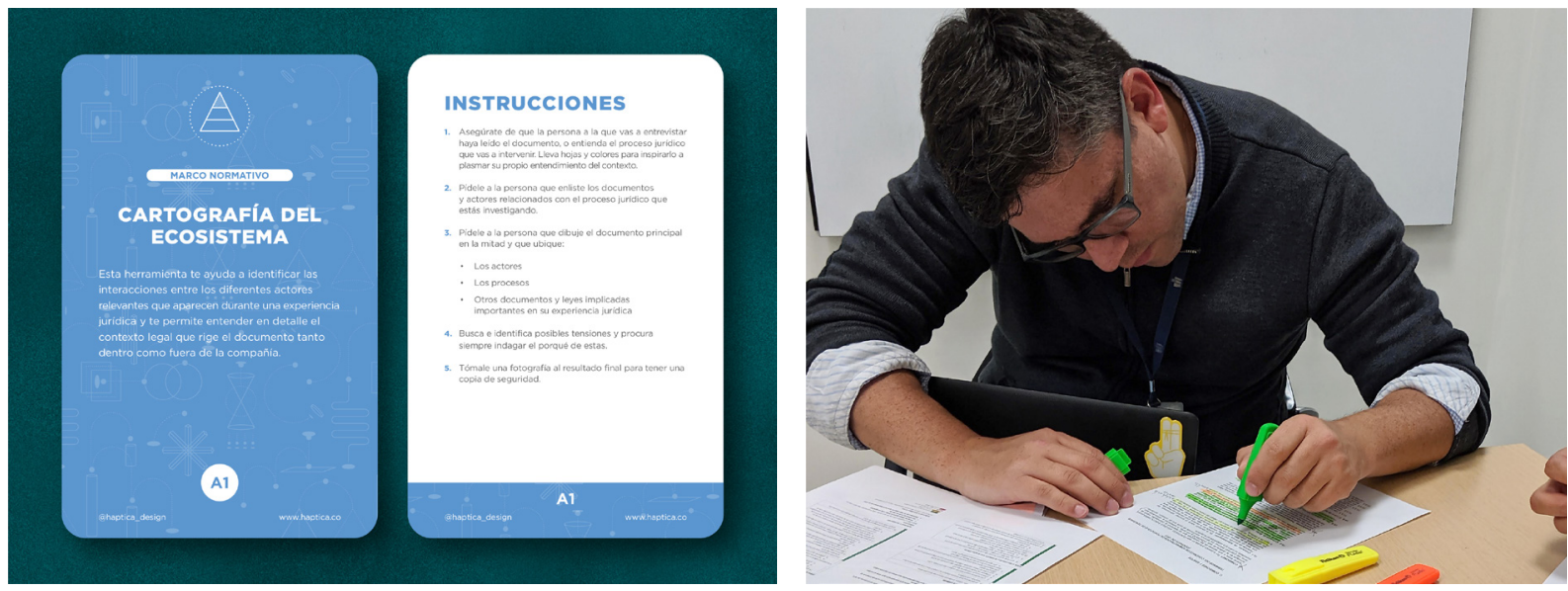

Figura 15. Herramienta: Cartografía del Ecosistema (Háptica, 2021)

Figura 16. Sesiones de trabajo de campo con uno de los clientes de Bancolombia. Se usó la herramienta Entrelíneas, entrevista a profundidad y naipe de conceptos (Háptica, 2021)
Dentro del sistema legal de la pirámide, recopilamos toda la información regulatoria relacionada con el contrato, con nuestra herramienta de Cartografía del Ecosistema (Háptica, 2021). En este taller, todos los abogados involucrados elaboraron una lista de las leyes que debían tenerse en consideración para saber cuáles son las restricciones legales para tener en cuenta en el Diseño y poder contextualizar al equipo de trabajo sobre el contexto legal que estábamos descubriendo. Se recopilaron tanto las leyes públicas como la información regulatoria del banco. Este aporte fue crucial para rediseñar la experiencia al final del proyecto, pues necesitábamos garantizar una intervención que reconociera el sistema legal al cual pertenecían los documentos que estábamos a punto de intervenir.

Después de explorar el sistema legal, pasamos al siguiente nivel de la pirámide: la experiencia de servicio. Para comprender este componente, nos reunimos con las partes interesadas clave del banco para discutir el recorrido completo del producto y los puntos principales de la historia. Entrevistamos a clientes, miembros del equipo de ventas y líderes legales del banco, con el objetivo de mapear todos los puntos de contacto: canales, personas, espacios, procesos y objetos relevantes para la experiencia.

El último nivel de la pirámide son los usuarios. Fue importante conocer realmente a los clientes, a los miembros del equipo de ventas y a los líderes legales del banco relacionados con este producto, porque el rediseño de estos documentos afectaba la experiencia de presentar, negociar y cerrar los tratos asociados. Frente a este punto actuamos como observadores durante el proceso comercial y luego discutimos la experiencia con el actor comercial para explorar cualquier duda y variación en el proceso.

Posteriormente, iniciamos la fase de análisis de la información recopilada. Durante este proceso, nuestro objetivo fue organizar la información y el contenido de referencias cruzadas para identificar conocimientos, aunque el principal desafío fue encontrar las implicaciones legales. Una de las herramientas claves fue el journey jurídico. Esto proporcionó la estructura para organizar los hallazgos con respecto a la experiencia completa y el papel del contrato en cada momento, de acuerdo con un cronograma del recorrido 

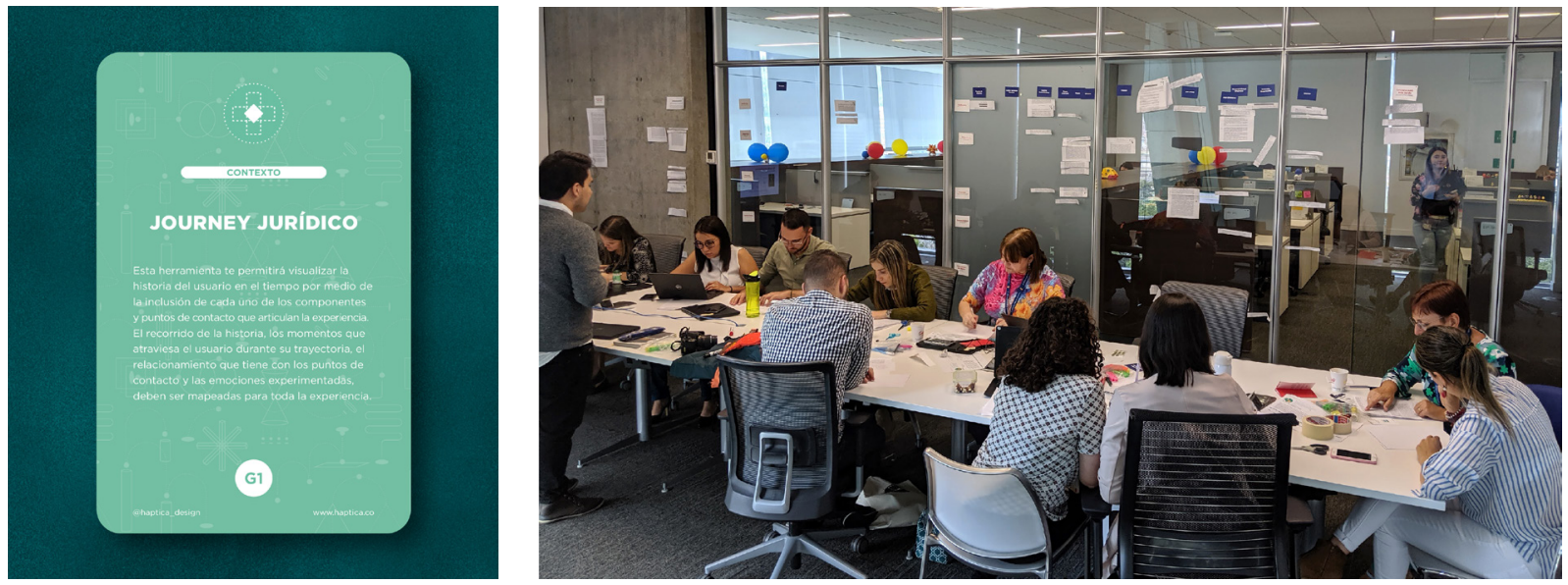

del cliente, para permitir así mapear áreas y actores claves que fueron fundamentales para implementar la solución final.

Una vez analizada y organizada la información, procedimos a iniciar la fase creativa de construcción y conceptualización de ideas que solucionaran las oportunidades identificadas. Este paso de la metodología fue fundamental para restablecer la nueva experiencia de nuestros usuarios por medio de los documentos legales. Lo logramos gracias al taller de cocreación, el cual nos permitió acompañar a los usuarios y partes interesadas mientras daban vida a un nuevo concepto de uso del documento y determinaban la interacción prevista entre los usuarios y el documento. El resultado fue un significado totalmente nuevo para el documento, mucho más que un simple acuerdo legalmente vinculante y que pudiera cumplir con fines/objetivos que en realidad les interesaban y servían a los usuarios no legales: volver un contrato en un documento de apoyo comercial para la fuerza de ventas del banco.

De esta fase ya teníamos los elementos necesarios para explorar la construcción de los primeros prototipos de solución. Durante la fase de especificación, se construyeron varios prototipos legales para definir los determinantes del Diseño y las metas del proyecto. Se realizaron sesiones de prototipado para evaluar la forma y el contenido del documento; se invitó a participar a abogados, partes interesadas comerciales, usuarios relacionados con el negocio y usuarios no legales. En una sesión, el grupo de abogados reconoció rápidamente las ventajas del nuevo documento.

Después de construir los prototipos del documento, entramos en la fase de acompañamiento, en la que trabajamos con personas que tenían contacto con el documento. Un requisito fundamental para el proyecto fue el Diseño de un documento operable para los actores relevantes que, posteriormente, iban a modificar o gestionar el documento. Estos actores son, en su mayoría, abogados que no tienen formación en Diseño y que suelen utilizar únicamente procesadores de texto básicos. Este fue un gran desafío para nuestros diseñadores de proyectos, ya que no suelen diseñar procesos con el objetivo de que el resultado final se gestione en programas básicos de procesamiento de texto como Microsoft Word.
Figura 17. Herramienta: journey jurídico (Háptica, 2021)

Figura 18. Taller de cocreación con el equipo del Bancolombia (Háptica, 2018) 
Figura 19. Ejemplo de los nuevos documentos diseñados; no solo intervenimos documentos legales sino también comerciales que hacían parte del universo documental (Háptica, 2019)

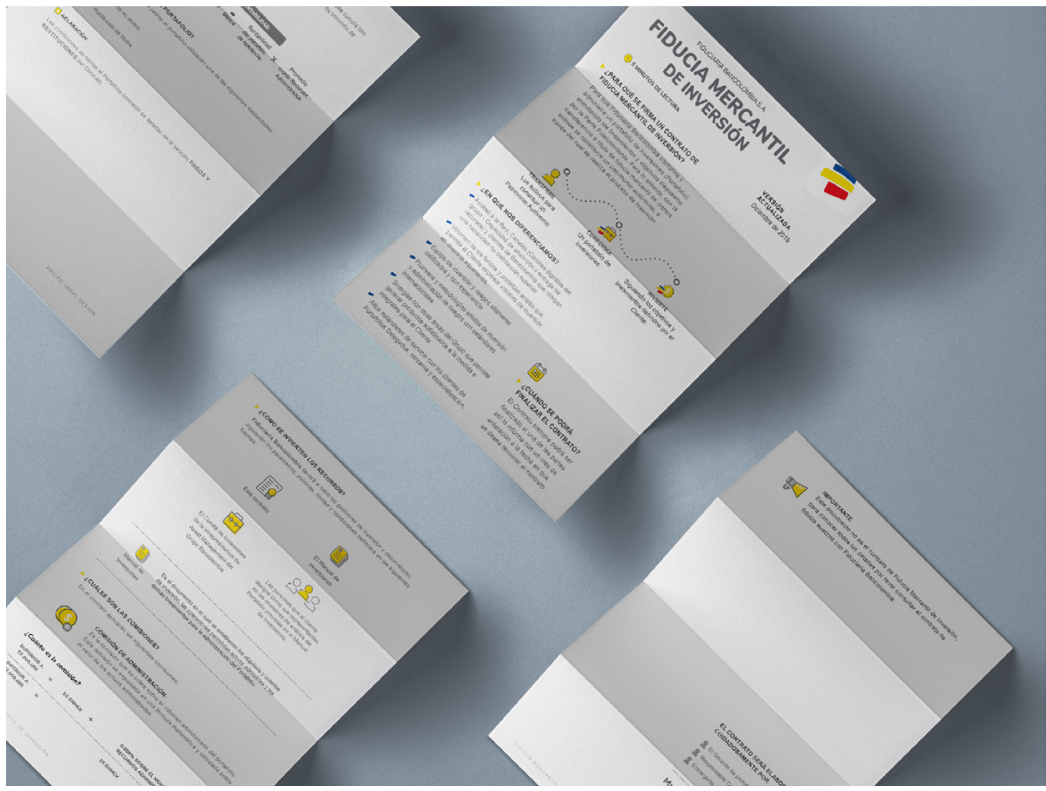

Bancolombia: sector privado, consultoría

Cliente

Osiptel

Objetivo Rediseñar tres documentos de alto impacto para el banco: uno masivo, otro que se relacionaba con el mercado de valores y un último que tenía que ver con negocios fiduciarios para garantizar proyectos licitatorios con el Estado.

Metodología

Entendimiento del ecosistema actual involucrado en la construcción de los documentos, que se relaciona actualmente con ellos, con el fin de cocrear la nueva versión de los documentos.

Herramientas

Entrevistas a profundidad, cartografía del ecosistema legal, entrelíneas, sombra, insights, journey jurídico, ADN del servicio, perfilación.

Por último, en la fase de evaluación, definimos los indicadores clave de rendimiento (KPIs por su sigla en inglés) que se utilizarán para medir el impacto del nuevo contrato, y lograr que en uno de los casos el producto se vendiera un $77 \%$ más gracias a la intervención en los documentos legales que lo rodean. Cada documento que se trabajó en este proyecto tuvo resultados operativos y de experiencia general de los usuarios muy satisfactorios. Desde una reducción considerable de los tiempos que tardan los documentos en ser revisados, aprobados y firmados por la contraparte, como los tiempos que tarda el equipo del banco en diligenciar su información. De igual forma, hubo mejoras importantes en la satisfacción general de los clientes que se enfrentan a estos documentos para poder entender de qué se trata el negocio $\mathrm{y}$ las condiciones a las que se comprometen al firmar.

Como resultado, ahora varios de los abogados del banco se llaman diseñadores legales. Desde la finalización del proyecto, se han rediseñado otros 25 documentos con el apoyo de líderes en innovación legal que surgieron durante este proceso, que quedaron con los insumos necesarios para trabajar sobre plantillas más visuales y con un mejor Diseño de la información. Algunas de esas iniciativas han requerido la aprobación de 


\section{Discusión}

\section{Cliente}

Osiptel

Bancolombia

UGPP
Privado

\section{Objetivo}

Rediseñar las guías de los contratos de los operadores de telefonía móvil para disminuir las quejas y equilibrar la experiencia entre operadores.

Rediseñar tres contratos con el fin de lograr eliminar obstáculos en la experiencia del cliente

Formar a los integrantes del área de cobro y embargos, con el fin de despertar empatía documentos claros y cercanos hacia el ciudadano y la importancia de generar

\section{Categorías}

Diseño documental

Formación

Formar a unos embajadores de la metodología para que pudieran desarrollar nuevos proyectos centrados en los usuarios.

la Superintendencia Financiera de Colombia, el regulador en el campo financiero, y los nuevos puntos de contacto legales han sido aprobados sin dudarlo, lo cual ha generado una tendencia en el mercado por migrar a estas implementaciones y las prácticas que esto implica.

Para analizar a detalle si deben hacerse diferenciaciones frente a la metodología cuando se trabajan proyectos de Legal Service Design en el sector público o privado creemos prudente hacer una subclasificación en el análisis. Para efectos de este estudio se tendrán en cuenta dos categorías: Diseño documental y formación.

\section{Diseño documental}

Comparación entre Bancolombia y Osiptel

- La metodología de la consultoría para Diseño documental no cambia: en ambos sectores usamos la misma metodología con algunas variaciones en herramientas, sin embargo, sí vimos obstáculos diferentes en cuanto a la implementación. En el sector privado el reto está más asociado a la aprobación por parte de entidades regulatorias, como es el caso de la Superintendencia Financiera de Colombia. En el caso del sector privado dependemos más de la voluntad humana de los actores involucrados, pues inicialmente se puede tener el poder legal de cambiar las cosas, pues ya eres la entidad regulatoria que dice como deben ser, pero te espera todo el camino asociado a la gestión del cambio. En el caso de Osiptel, fue la tenacidad de Noemy Espinoza la que hizo posible este proyecto, pues ella fue la que nos contactó, consiguió los recursos para movernos a Perú, consiguió la agenda de toda el área legal de la entidad, pero más importante incentivó la generación de la resolución y gestión del cambio dentro de las entidades de telefonía móvil para que la hicieran realidad.

- El valor de los equipos interdisciplinarios del sector privado: generalmente las personas que son contratadas en entidades públicas son asignadas para determinado rol particular. Pedir la colaboración para participar fuera de este marco de acción es un poco difícil porque estaría actuando extracontractualmente; estas barreras no se ven en el sector privado. Por el contrario, vimos algo completamente diferente en Bancolombia: todas 
las áreas que de alguna u otra forma tenían relación con el documento que afectaba la experiencia del cliente querían involucrarse y participar del proceso de diagnóstico, de cocreación y de validación. Esto permitió que tuviéramos una aproximación interdisciplinaria que hoy en día buscamos asegurar en todos nuestros proyectos de Legal Service Design.

- La diferencia de los retos: para las entidades privadas generalmente el cliente es el usuario final que va a leer los contratos o los documentos legales. En el caso de Bancolombia no era necesario aclararle a los actores del Banco por qué era importante entender las brechas entre lo que decía el documento y lo que entendía el usuario. En las entidades públicas regulatorias, puede que haya una brecha más grande: hay un actor adicional en la mitad que es la entidad privada que presta el servicio, y es posible que no sea claro quién es el usuario y sobre todo por qué es importante y qué necesita. En este caso, la razón por la cual Osiptel nos buscó fue porque tenía una cantidad de quejas que iban incrementando con el tiempo, porque los ciudadanos aceptaban términos y contratos de entidades financieras sin leerlos ni entenderlos, lo cual generaba confusiones y problemas que terminaban reportándose ante el mismo Osiptel. Este indicador le visualizó claramente un problema a la entidad pública, que le hizo ver una oportunidad de innovación donde ellos podían tener un rol relevante que finalmente beneficiaría al usuario final. Pero este no es el caso del $100 \%$ de las entidades públicas.

- Ambos proyectos se miden en cantidad de documentos firmados: el indicador utilizado para medir el impacto del proyecto de Osiptel corresponde a la cantidad de contratos cortos que se han logrado firmar al 8 de agosto de 2020 , que corresponde al $83 \%$ del total de las ventas de productos de telefonía móvil. En el proyecto de Bancolombia se midió el tiempo que se demoran las personas en firmar el documento y, por consiguiente, cómo aumentó el número de contratos firmados en determinado tiempo, con impacto en las ventas de determinado producto.

- La magnitud del cambio: en Háptica hemos desarrollado más de 10 proyectos con Bancolombia y conocemos de cerca su rigurosidad en la implementación de los proyectos de consultoría. En el caso de Osiptel, solo tuvimos esa semana, hicimos nuestro entregable y no teníamos claridad de cuáles serían las pautas de la implementación. Para lograr su implementación tuvieron que generar resoluciones, realizar gestión del cambio con todos los operadores de telefonía móvil dentro del país y lograr asegurar un entendimiento de las nuevas guías para su desarrollo. Con este proyecto se logró un impacto a nivel nacional con todas las entidades relacionadas con esta experiencia en particular. Con el proyecto desarrollado en Bancolombia hicimos algo muy poderoso, pero lamentablemente sólo benefició a sus clientes.

- Resultados sistémicos vs. inmediatos: el impacto en los proyectos públicos tiende a tardar más tiempo en su implementación y son más difíciles de coordinar entre equipos que deben ponerse de acuerdo para iniciar una nueva implementación. Sin embargo, una vez concluidos, su impacto genera por lo general un cambio en el sistema, ya que estamos 
en el contexto de entidades públicas que tienden lineamientos o modelos marco para que los privados puedan seguir. Por el contrario, en el caso de los proyectos de Legal Service Design privados tenemos resultados que, si bien impactan incluso modelos de negocio en una empresa, el reto se contiene en la capacidad empresarial para sacarle provecho a la implementación a través de sus propios recursos.

\section{Formación}

Al comparar UGPP y Gómez Pinzón, encontramos que:

- La metodología de formación es la misma: la metodología implementada para ambas organizaciones fue bastante similar, pues consistió en un programa de formación donde se entrenaron a unos embajadores con el fin de que pudieran empoderarse del método y generar un impacto en los productos o los servicios ofrecidos por la entidad o la organización. La única diferencia radical fue que en Gómez Pinzón ellos hicieron su trabajo de campo y en UGPP nosotros lo hicimos por ellos y construimos unos expedientes para que pudieran tener acceso a los insumos relacionados con las necesidades de los usuarios.

- Las barreras mentales para aprender del abogado son las mismas en el sector público y privado: en ambos casos cuando iniciamos los procesos de formación fue retador porque las áreas que vincularon a Háptica con las organizaciones no fueron las áreas legales sino áreas de innovación o de experiencia de clientes, por consiguiente, lograr convencer a abogados sobre la necesidad de formarse en estas metodologías fue igual de retador en el sector público y privado. Por ejemplo, los abogados de la firma sentían que ellos no necesitaban innovar y que esto era algo que debía corresponder al área de mercadeo, pero conforme empezaron a asistir a las sesiones y a empoderarse del trabajo de campo descubrieron que este también podía ser su rol dentro de la compañía. En el caso de la UGPP pasó lo mismo, pero porque el abogado tenía un rol más de castigador, entonces no se veían a sí mismos como los que podían guiar o enseñarle al cliente sobre su proceso de pago. Sin embargo, el método los involucró activamente hasta la construcción de prototipos que hoy en día hacen parte de la cotidianidad de la organización.

- La burocracia y la auditoría del sector público pueden ser beneficiosas: para nadie es un secreto que el sector público se caracteriza por sus procesos y jerarquías exigentes, y el caso de la uGPP no es la excepción. Para que este proyecto de formación fuera aprobado tuvo que hacerse un proceso de contratación vigilado y asignación presupuestal auditada, pero lo más relevante es la exigencia de resultados después de haber hecho la inversión. Al tratarse de recursos públicos, era muy importante hacer evidente qué se había logrado con esa inversión. Por esto le dieron tanta relevancia a la medición y este fue un incentivo que movilizó a las áreas para tener un mensaje incluyente, usar componentes visuales y lograr comunicaciones más claras que le permitieran al usuario entender mucho mejor su contenido. 
- Las horas de formación tienen un valor diferente en el sector público y privado: en una firma de abogados tradicional, parte del modelo de negocio es la facturación por horas, lo cual implica que cuando se decide formar a 25 personas, se impide que éstas facturen y produzcan. Este fue uno de los obstáculos a los que nos enfrentamos con la firma, donde muchas veces la reunión con el cliente era prioridad sobre las horas de clase. En contraste, la formación en el sector público se ve como un avance en el escalafón y como una inversión en el recurso interno, lo cual es beneficioso para ambas partes, por eso el índice de asistencia fue mayor en el sector público que en el privado.

- La motivación está relacionada con la reputación en ambos sectores: cuando indagamos el por qué decidieron realizar el proyecto, ambas entidades buscaban diferenciación, pero la entidad del sector privado ligaba esta diferenciación con un tema de posicionamiento en el mercado, lo cual podría tener una implicación asociada a las ventas. Por otro lado, la entidad pública busca que esa reputación le genere reconocimientos con sus pares y frente al ciudadano como tal.

- La implementación es más lenta en el sector público pero genera más impacto que en el privado: al formar a un grupo de personas con un nuevo método dependemos de muchos factores externos para que este conocimiento se materialice en acciones puntuales, pero claramente es mucho más lento cuando hablamos del sector público que cuando lo hacemos del sector privado. En el sector público cualquier cambio que los integrantes de la entidad quieran hacer se puede demorar el doble del tiempo que se toma en una organización privada, pues puede que incluso sea necesario hacer modificaciones legislativas para lograr la implementación requerida. Una vez que se supera el proceso burocrático, el impacto de un proyecto proveniente del sector público llega a miles de ciudadanos, como es el caso de las comunicaciones generadas por la UGPP.

\section{Conclusiones}

El origen de este análisis estaba enfocado directamente en identificar si la metodología cambiaba o si debía cambiar cuando tratamos con proyectos bajo el marco de Legal Service Design frente a iniciativas del sector público y privado. Hemos descubierto que los cuatro proyectos seleccionados, dos para Diseño documental y dos para formación, son exitosos y fueron trabajados bajo el mismo marco metodológico, así que podríamos decir que no es necesario hacer una diferenciación metodológica sustancial.

No obstante, sí vemos unas oportunidades para potencializar aún más proyectos en el sector público y privado cuando nos enfrentamos a proyectos de formación y consultoría, respectivamente.

En cuanto a formación

- En proyectos públicos de formación, e incluso de consultoría, deberíamos darle mucha más relevancia al tema de la medición, porque es lo que generará los incentivos de implementación de la metodología. Recordemos, 
en el caso de la UGPP vimos que al ser una entidad que maneja recursos públicos es auditada y necesita demostrar el impacto de su inversión. Recomendamos siempre incluir en los cronogramas la medición del impacto de los proyectos.

- Como las entidades públicas son auditadas, esto genera una presión superior e incentiva la implementación de los proyectos y el seguimiento a los mismos, como vimos en la UGPP y en el indicador que debía mover Osiptel con sus quejas y reclamos. Proponemos identificar qué incentivo debería ser el motivador dentro del sector privado para incentivar la implementación masiva de los proyectos que desarrollamos dentro del marco de Legal Service Design.

- Deberíamos hacer un refuerzo con metodologías asociadas a gestión del cambio en ambos sectores, particularmente en el sector público cuando se tienen que hacer conciliaciones interentidades, pues uno de los retos más grandes a los que se enfrentó la UGPP fue mantener el espíritu y lograr mantener vigente la necesidad de realizar un cambio dentro de la entidad. Recomendamos explorar la metodología de John Kotter (1995). Esto también aplica para los proyectos de consultoría, pues uno de los méritos más grandes fue la transformación masiva que logró Noemy Espinoza, de Osiptel, con las entidades de telefonía móvil en Perú. Esto es posible gracias a su mandato como entidad reguladora. Es trascendental lograr un cambio estructural y que venga desde la convicción de que hay un objetivo asociado a las necesidades del ciudadano y unos pasos para alcanzarlo.

En cuanto a consultoría

- En Háptica hemos desarrollado 38 proyectos de Legal Service Design y sólo tres han sido con entidades públicas, pero es evidente que los impactos más grandes se logran con éstas. Después de haber hecho este análisis comparado, hemos descubierto la necesidad de tener una visión mucho más sistémica del Legal Service Design, donde debemos promover el desarrollo de proyectos que trabajan directamente con entidades públicas y los reguladores, con el fin de lograr el impacto que la ciudadanía se merece. Para lograr esto, es fundamental incluirlos desde el inicio en los proyectos de sector público para que vean el valor en la implementación del método y posteriormente sean ellos los que tengan la iniciativa de generar un cambio más contundente que abarque a todo el sector, como lo logró Osiptel y sus 2,51 millones de contrataciones efectuadas bajo los nuevos lineamientos que realmente se centraban en las necesidades del usuario.

- Seguramente el proyecto de Osiptel hubiese sido aún más potente si hubiese sido posible involucrar a otras áreas de la organización en los procesos de transformación. Por esto es fundamental que haya mayor apertura en los procesos de consultoría por parte de las entidades públicas para incluir áreas diversas, así no estén aparentemente relacionadas con puntos de contacto legales. Los ejercicios que se hicieron con equipos como el de Bancolombia demostraron eficiencias en tiempos, diversidad en las ideas y, sobre todo, un efecto dominó con otras áreas que hoy llevan 
el Legal Service Design a toda la organización. Todas las organizaciones públicas necesitan esta metodología en cada una de sus divisiones, y un proyecto puede ser el detonador para iniciar esas conversaciones.

\section{Nota de las autoras}

Cada vez que un cliente contacta a Háptica para llevar a cabo un proyecto, deposita un voto de confianza. Estos cuatro proyectos no son la excepción y, para ser honestos, es aún más contundente el tipo de vínculo que generamos porque estamos frente a un método nuevo en Latinoamérica, donde exploramos herramientas y metodologías constantemente, y es con los clientes que tenemos la oportunidad de prototiparlas. Queremos aprovechar este espacio para agradecer a las siguientes personas:

- Luz Dary Mendoza, Directora de Servicios Integrados al Ciudadano de la Unidad de Gestión de Pensión y Parafiscales (UGPP), participó activamente en el proyecto y quiso además colaborar en la escritura del impacto actual del método en la entidad. Luz Dary es una excelente embajadora de la metodología dentro de la organización y ha logrado instaurar el indicador de claridad, que se logra cumplir gracias a la materialización de las reglas de oro construidas bajo el programa de formación.

- Mauricio Jaramillo, Socio de Gómez Pinzón e integrante del comité de innovación de la firma de abogados, fue uno de los principales embajadores del proyecto desde sus inicios y actualmente es uno de los que lleva en alto el título de multiplicador para materializar los aprendizajes por medio de puntos de contacto legales que permiten que el servicio de Gómez Pinzón sea diferente y mucho más cercano a sus interlocutores.

- Noemy Espinoza, especialista en inversiones y procesos de innovación en Osiptel, fue la que nos abrió las puertas dentro de la entidad y nuestra primera cliente en Perú. Ella logró materializar este importante proyecto que ahora permite a sus ciudadanos entender los términos y condiciones de los documentos legales asociados a los servicios de telefonía móvil e instaurar una nueva cultura dentro de estas entidades privadas.

- Nicolás Venegas, legal designer y multiplicador de innovación en Bancolombia, ha sido nuestro cliente en varios proyectos. Ha logrado la implementación de las iniciativas que ha desarrollado con Háptica y ha logrado instaurar una cultura de Legal Service Design dentro de la organización y dentro del sector financiero en Colombia.

- Maria Camila Venegas, directora estratégica en Háptica, dirigió los dos proyectos del sector público que se incluyen en esta publicación y ha hecho posible la materialización de más de 90 proyectos en la compañía. Sin ella Háptica no sería lo que es. 


\section{Referencias}

Agudelo, N. \& Lleras, S. (2015). Para el salón: Herramientas para el diseño centrado en el usuario. Edición Uniandes.

Armitage, A., Cordova, A.K. \& Siegel, R. (2017). Design

Thinking: The answer to the impasse between innovation and regulation. Georgetown Law Technology

Review, 2(1), 3-63. https://repository.uchastings.edu/ faculty_scholarship/1569/

Beckman, S. \& Barry, M. (2007). Innovation as a Learning Process: Embedding Design Thinking. California Management Review, 50(1), 25-56. https:// isfcolombia.uniandes.edu.co/images-/documentos/ designthinkingdoc.pdf

Háptica. (2021). Toolkit de Legal de Service Design. https:// haptica.co/product/el-toolkit-de-legal-service-design/

Kotter, J. (1995). Leading Change: Why Transformation Efforts Fail. Harvard Business Review, May-June 1995. La Unidad de Pensiones y Parafiscales [UGPP]. (2021). https://www.ugpp.gov.co/

Marvelapp. (2021). https://marvelapp.com/ Oficina de Comunicaciones y Relaciones Institucionales. (21 junio 2021). OSIPTEL: más de dos millones de nuevos contratos cortos se emitieron para servicios fijos y móviles en junio. Organismo Supervisor de Inversión Privada en Telecomunicaciones [OSIPTEL]. https://www.osiptel.gob. pe/portal-del-usuario/noticias/osiptel-mas-de-dosmillones-de-nuevos-contratos-cortos-se-emitieronpara-servicios-fijos-y-moviles-en-junio/

Penin, L. (2018). An Introduction to Service Design: Designing the Invisible. Bloomsbury Visual Arts.

Resolución de Consejo Directivo 153-2020-CD/OSIPTEL [Presidencia del Consejo de Ministros y Organismo Supervisor de Inversión Privada en Telecomunicaciones, OSPITEL]. Norma que sustituye el artículo 17 del texto único ordenado de las condiciones de uso de los servicios públicos de telecomunicaciones. 19 octubre 2020.

Snyder, C. (2003). Paper Prototyping. The Fast and Easy Way to Design and Refine User Interfaces. Morgan Kauffman. 